intentions is very clear and precise. He assigns, in his will, intent. a year as the salary of a reader in anatomy; $50 l$. for ex$100 l$. matics and physics, and the remainder to be given in annual prizes of $10 l$. to scholars from Westminster School. The trust is now worth $3,400 l$. annually. It is spoken of in the return nade by Christ Church to the Commissioners of 1874 as "Dr. Lee's Benéaction for Senior Students in Natural Science," This is not quite accurate : firstly, because Dr. Lee designed the major portion of his benefaction for students in anatomy as bearing on medicine, and not for natural science generally; and, secondly, because Christ Church uses nearly half of Dr. Lee's trust-money to pay classical scholars from Westminster School ; whilst the remainder is used to support a most efficient chemical laboratory, and to pay, in part, the salaries of the accomplished chemist, zoologist, and physicist, who are styled "Lee's Readers." No part of Dr. Lee's bequest is now assigned to medical studies, though it should be stated that the present application of Dr. Lee's fund has obtained Parliamentary sanction.

\section{ON THE THERMAL PHENOMENA PRODUCED BY THE PASSAGE OF ELECTRICITY
THROIGH RAREFIED GASES}

A PORTION of the experiments described in this paper were A made before the publication of Wiedemann's experiments on the same subject. The authors state that if they had known of the work of the German physicist they would probably not have undertaken the investigation, but they have continued the experiments and think them w'orthy of description as the methods exiployed differ from those of Wiedemann.

The apparatus used consisted of ordinary Geissler tubes, the electrodes beinc in wide tubes connected by a narrow one. A large Ruhnakorf's coil with a secondary wire 100,000 metres in length was set in action by two large Bumser cells, and the current was made and broken by a Foucault's interrupter. In orrier to measure the induced current a reflecting galvanometer was einployed, being placed at such a distance from the coil that the effect of the electro-magnet on the needle was very small; this slight deviation was, however, applied as a correction in all the readings. It was first proved that the current induced on completing the primary circuit was incapable of passing through the Geissler tube, for the galvanometer needle was equally deflected whether placed in tbe secondary circuit o: not, indicating that the movement of the needle was due solely to the direct action of the magnet of the coil; on the contrary, when the primary circuit was broken, "considerable deffection of the needle occurred when the galvanometer was in the secondary circuit, and a slight one, but in the opposite direction, when the needle was influenced by the magnetisin of the coil alone.

Tubes containing chlorine, carbonic anlyydride, and hydrogen, were employed in the experiments, the electrodes being soldered to the wires from the coil by means of Wood's fusible alloy. The narrow part of the tube was placed in a copper cylinder containing water, or preferably mercury, in which a delicate themometer was immersed, the deflection of the galvanometer was read every thirty seconds, and the thermometer every minute. When the current indicated by the galvanometer was greatest the increase of temperature was most rapid, but the important fact shown by these experiments is that in every case the rise of temperature divided by the deflection is a constant. Unfortunately the different constants are not comparable, as the experiments were not made with the same tube containing the different gases at known pressures, but with different tubes of nearly the same sizes; but the pressures of the gases are not given.

Some experiments were undertaken to determine the heating effects in the neighbourhood of the electrodes. For this purpose the upper end of a Geissler tube containing chlorine was placed in the calorimeter, the latter surrounding the part of the tube containing the platinum wire. When the electrode was negative about eight times more heat was developed than when it was positive. As the quantity of heat produced when the electrode was positive was very small the relation between the deflection of the galvanometer and the rise of temperature was not so regular in the different experiments as in the other case; and when the electrode was negative it was observed that the quanI By Dr. Naccari and M. Bellati (vol. iv. ser. v., degli Atti del $R$. Iusti. tuto veneto de Science, Letterz ed Arti). tity of heat increased a little more rapidly than the defection. More accurate results were obtained by immersing the lowe: end of the tube in the calorimeter; under these circumstances the quantity of heat collected when the electrode was negative was 22.8 times as great as in the experiments in which it was positive, and while the deflection of the galvanometer varied from 100 to 640 , the rise of temperature divided by the deflections increased from roo to 120 only.

It being suspected that the different effects at the two elec. trodes might be due to a cause similar to the Peltier effect in solid conductors, an attempt was made to discover if the positive electrode is cooled during the passage of the electricity. There appeared to be a very slight diminution of temperature at the commencement of the experiment, but it was soon marked by the conduction of heat from other parts of the tube.

The calorimeter was next placed on the wide part of the Geissler tube, but not surrounding the electrode, which was $16.5 \mathrm{~mm}$. from the calorimeter. In this case, also, a larger. quantity of heat was developed near the negative electrole than near the positive, but the ratio was only $4{ }^{\circ}$. When a portion of the narrow part of the tube was placed in the calorimeter, that near the negative electrode was slightly more heated than the other portion. When a tube containing hydrogen was used similar results were obtained, but the difference between the quantities of heat at the two ends was very much less than in the case of chlorine.

The next series of experiments was made to determine the effect of different diameters of tube. For this purpose a U-tube containing air of the pressure of two $\mathrm{mm}$. was used, one limb of the tube having a sectional area of $36^{*} 3$ square mm., the other 12.6 square mm., both limbs being surrounded by calorimeters. The quantity of heat developed in the narrow tube was only very slightly greater than in the other, the ratio being about $r \cdot r$. By using another tube with the areas of $1 \times 6.9$ square mm. and $4^{\circ} 5$ a similar result was found, but in this case the ratio was not greater than $x \cdot 2$.

\section{NOTES FROM NEW ZEALAND}

THE following notes have been sent tis from New Zealnd by Mr. T. H. Potts, of Ohinitahi :-

Intaori Food Feast.-At the great meeting of Kingite natives convened by Tawhaio to meet Sir George Grey and the Fion. Native Minister, amongst other very interesting incidents was the food feast which was held at Hikurangi on May 8.

A procession formed of several hundreds of women, each carrying a neatly woven basket filled with food, proceedled through the villaye till it arrived opposite to Sir Georce Grey's tent; at a given signal the baskets were placed on the gromal and stacked into a huge heap. The presentation of each artic!e of food was accompanied with an appropriate chant or ngori, with dancing and facial contortions of an extraordinary character, many of the most ancient persons of different hapus taking part in the celebration.

Amongst the various articles of vegetable food in season was offered:-

Poluta. -The root of Contolvulus sepium, as flowery as a potato with a slightly bitter taste.

Sozuthistie.-Sonchus oleraceus. The Haubaus, when com. pelled to use cooked sowthistle, found to their surprise they did not lose condition on this spare diet.

Para. - The thick solid scale from the rootstock of the grand fern Marattia fiaxinea. This edible was pinkish or pale purple when cut, solid, tough, almost tasteless, with a slightly bitter flavour.

Marnaku.-This esculent appeared in thick junks of about a foot in length; it is the mucilaginous pith of the great black tree-fern Cyathea medullaris. It was presented ready dressed, was soft, very sweet to the palate.

Roi.-The rhizome or root of the bracken Pteris aquilina, var. esculenta. It was offered in the uncooked state, in which it is usually kept ready for use.

Tawha.-The prepared berries of a common forest tree Nesodaphne tawhic.

Hakeke. - The Jew's-ear fungus Hirnoola auricula-Fude. It is found in the forests of Pirongia; that which grows on the Karaka is most esteemed.

On Mon Remains, Ec. - There has been so warm a controversy as to the probable date fof the extinction of the dinornis, that 
any reliable fact connected with the remains of the wonderful animals may be of value to the biological student. $\vec{E}$

On the low hills and flats north-east of the gorge of the Raliaia, from 1854 to $185^{8}$, there were quantities of gizzardstones lying in small heaps on the surface of the ground; for years no one collected them for scientific purposes, but boys or bush-hands sometimes turned over the heaps, and picked out a "few pretty ones" that happened to take their fancy.

In April, 1857, with two friends, I went up the course of the Rakaia, followed the southern stream, then through the country west of Mount Hutt and Mount Somers, returned to the "plains" by the Ashburton or Haketere River; this was then all new comntry, not taken up. On the southern side of the Ashburton or Haketere River, on the flats above the gorge, a vast number of moa bones lay exposed on the sturface of the soil; after I had taken up a run there, I used frequently to pick up specimens from amongst these bones and throw them into heaps, with the view of maling a selection therefrom at some future time.

It may be worth mentioning that near that spot, at a now wellknown place called "Paddle Hill," I found a paddle made of totana (Podocarpus totana), with a longer handle and much broader blade than any hoe that $I$ have seen used by natives it seemed too large for a paddler kneeling or squatting; it had probably been used to propel a moki or raft.

The Pahu.-The Hauhaus at the Hikurangi meeting were called to their place of worship by the beating of the pahu; it is a long, sonorous piece of wood, made (when possible) from an aromatic tree called porokaiwhiria (Hedycaria dentata). It is hung from a cross pole supported at either end by a forked siick. The sonnd may be heard to an extraordinary distance. It is produced from this rough kind of wooden drum being beaten on its edges by several persons furnished with short batons.

\section{UNIVERSITY AND EDUCATIONAL INTELLIGENCE}

THE Cambridge Syndicate appointed to consider the higher mathematical studies and examinations of the university bave issued a further report in which they state that they have been led by the observations of members of the Senate in the Arts School, and by the results of the voting on the scheme of examination recommended in their report of March 29, to believe that in the opinion of the Senate the examination in Part III. of the Mathematical Tripos should be independent of the preceding parts, and also that the Senate would be averse to any scheme in which it was not provided that all the smbjects should be included in the examinations of each year. They have framed regulations in accordance with these principles in substitution for those rejected by the Senate on May 29, under which it is provided that from the results of the examination in Parts I. and II., the candidates shall be arranged in order of merit as Wranglers, Senior Optimes, and Junior Optimes. Only Wranglers are to be admitted to the examination in Part III., and from the result of the examination in that part only, the Moderators and Examiners shall publish in three divisions, each division arrauged alphabetically, a list of those examined and approved. Fower is given to the Moderators and Exa. miners to place in the first division any candidate who has shown eminent proficiency in the subjects of any one group in Schedule III. In each of the papers in bookwork in Part III. a limit is to be fixed to the number of questions to which any candidate shall be permitted to send in answers, such limit to be printed at the head of each paper. The subjects in Part III. are grouped in four divisions. Group A consists of differential equations, calculus of variations, higher algebra, higher parts of theory of equations, higher analytical geometry (plane and solid), finite differences, higher definite integrals, elliptic functions, theory of chances, including combination of observations. Group B, Laplace's and allied functions, attractions, higher dynamics, Newton's "Principia," book i. sec. ix.-xi., lunar and planetary theories, figure of the Earth, precession and nntation. Group C, hydrodynamics, inclucling waves and tide, sound, physical optics, vibrations of strings and bars, elastic solids. Group D, expre:sion of functions by series or integrals, involving sines and cosines, thermociynamics, conduction of heat, electricity, magne tism. From the discussion which took place on the subject on November 2, opinion seems to be pretty much divided at Cambridge as to the advisability of the proposed alterations.
A Post-mastership at Mierton College, Oxford, for Natural Science, has been awarded to Mr. Geo. Howson, a pupil of Giggleswick School.

\section{SCIENTIFIC SERIALS}

Memorie della Societì degli Stettroscopisti Italiani, A pril, 1878, contains a table showing the solar spots and facula for each day of observation for the months of January, February, and March 1877. A note by Prof. Tacchini on the solar spots of the first three months of 1877 , compared with those of the same months in 1878. - An account of the observations of solar prominences made at Palermo during the first three months of the present year.-Drawings of the chromosphere for the months of March, April, May, and June, $187 \mathrm{I}$.

May. - This number contzins full accounts of the transit of Mercury of May 6, 1878, as observed at Rome, with notes on the same by Respighi, St. Ferrari, Millosevich, and Tacchini. -Drawings of the chromosphere for June and July $\mathrm{i} 87 \mathrm{I}$.

June.-Tables of solar spots and faculae for April and May, IS78.- Note on the spots and solar eruptions of April, May, and June, 1878 , by Prof. Tacchini. - A long paper on a cause for the appearance of bright lines in the solar spectrum, by Mr. Meldola.

July.-A paper containing tables of the solar prominences observed at Palermo in April, May, and June, 1878, by Prof. Tacchini.-A long paper by Schiaparelli on the observations of the rotation and topography of the planet Mars made at Milan during the opposition of $\times 877$.

August. - Spectroscopic observations of the chromosphere made at Palermo during the months of April, May, and June, IS78. Tables showing the number of protuberances and spots on the stin for each day of observation for the months of August, September, October, November, and December, as seen at Rome, with notes thereon.-Drawings of the chromosphere for the last part of July, 1871, made at Palermo.

Bulletin de l'Acalénie Royale de Belgique, No. 7, 1878.-... It has been affirmed by more than one observer that, during aurora boreales, the intensity of scintillation of stars las been considerably increased; a singular inflaence, if real. M. Mon. tigny, testing such statements, observed twice such an increase (en the nights of April 5, 1870, and June 1, 1878). He notes the fact that this increase coincided with a lowering of temperature of the air in the locality. In the one case this fall occured exactly at the moment of the aurora and observation of the scintillation; in the other case it preceded the aurora, but was more marked the night of it, and a few hours after observation of the increase in question. He considers the increase due to the cooling, which must have affected first the upper regions of the atmosphere through which the stars' rays pass; and this arrees with the fact that the stars fuxthest above the horizon showed the increase most.MM. Spring and Durand study some obscure points in the composition of oxygenated compounds of nitrogen. Finding that the products of reaction, with water, of the body formed by action of chlorine on nitrite of silver, are exclusively nitric acid and chlorhydric acid, their sumise was verified that the chlorine is substituted for the silver of the nitrite, atom for atom, forming nitric chloride. Hence the structure of the group $\mathrm{NO}_{2}$ of nitric acid is inferred to be the same as that of its correspondent nitrons acid, and the rational formula of these two substances must be written respectively HO.N $=\mathrm{O}$ and HO.O-N $=\mathrm{O}$. $\mathrm{M}$. Melsens seeks to refute M. du Moncel's statements about the cost of his system of lightning-conductors, as applied to the Hotel de Ville, in Brussels, and criticises the instructions of the Paris Commission for erecting conductors on public buildings. - Some letters in a controversy between M. du Moncel and MM. Navez on the theory of the telephone, appear in this number.-M. Malaise announces the discovery of Brachiopoda of the genus Lingula in the Cambrian formation of Stavelot.

No. 8. - The digestion of albuminoids in some invertebrates forms the subject of a paper here from Dr. Fiedericq. From a combination of his results with those got by Hoppe-Seyler and Platean, it appears that the mechanism of digestion is the same throughout the animal kingciom, and the transformation of food in invertebrates is effected through substances that have the greatest similarity to the digestive ferments of vertebrates (solubility in water, precipitation by alcohol). Digestion by means of 